\title{
ANNOUNCEMENTS AND NEWS NOTES
}

1. This issue of Astin Bulletin is the first one of Volume 14, which originally was scheduled for publication in 1983, whereas now it is associated with 1984 . The reason for a redesign of the publication schedule of our journal originates in the fact that Astin Bulletin has been structurally half a year behind on publication schedule for the past years, which was due to a lack of papers of sufficient quality to be published in our journal.

We like to publish only papers which are worth reading and rereading.

The second issue of Volume 14 is planned for October 1984.

2. Recently, the Index Astin Bulletin 1957-1982 has been published. We hope that this index will be of value in searching for earlier contributions in the field of non-life insurance and risk theory.

The new rules of Astin also are included in this index.

3. At the 17th Astin Colloquium in Lindau (West Germany) Charles A. Hachemeister (USA) was elected as a member of the Committee of Astin.

Jan Jung (Sweden) and Ragnar Norberg (Norway) resigned as members of the editorial board of our journal. Jan Jung has been an active member of this board as from 1976 and the present status of Astin Bulletin owes a lot to him. Although Ragnar Norberg only served for three years as a member of this board, the level of his excellent referee reports will remain a model for the future.

In order to avoid any attrition of the editorial board of Astin Bulletin, the Committee of Astin has appointed Björn Ajne (Sweden), Jukka Rantala (Finland) and Bjørn Sundt (Norway) as new members of this board.

P. TER BERG 